\title{
PENGARUH KEPEMIMPINAN TRANSAKSIONAL, BUDAYA ORGANISASI, DAN KOMUNIKASI TERHADAP KINERJA KARYAWAN
}

\author{
I Komang Alan Darmasaputra ${ }^{1}$ \\ I Gede Adnyana Sudibya ${ }^{2}$
}

\author{
${ }^{12}$ Fakultas Ekonomi dan Bisnis Universitas Udayana (Unud), Bali, Indonesia \\ email: alandarmasaputra32@gmail.com
}

\begin{abstract}
ABSTRAK
Kemampuan pemimpin dalam gaya kepemimpinan transaksional yang rendah, dan budaya organisasi yang kurang jelas sehingga sulit dipahami oleh karyawan, serta komunikasi antar karyawan atau pimpinan dengan karyawan yg kurang baik dapat menimbulkan lemahnya kinerja perusahaan. Melemahnya suatu kinerja perusahaan akan berdampak pada pencapaian tujuan perusahaan dan keberhasilan suatu perusahaan tersebut. Penelitian ini bertujuan untuk mengetahui pengaruh kepemimpinan transaksional, budaya organisasi, dan komunikasi terhadap kinerja karyawan CV Nusa Kampial. Penelitian ini dilakukan di CV Nusa Kampial dengan jumlah karyawan sebanyak 35 orang. Pengumpulan data dilakukan dengan metode wawancara dan penyebaran kuisioner. Analisis data menggunakan uji asumsi klasik, regresi linier berganda, uji f, r square dan uji t. Hasil penelitian ini ditemukan bahwa kepemimpinan transaksional berpengaruh positif signifikan terhadap kinerja karyawan, Budaya organisasi berpengaruh positif signifikan terhadap kinerja karyawan dan Komunikasi berpengaruh positif signifikan terhadap kinerja karyawan. Pihak perusahaan hendaknya dapat meningkatkan gaya kepemimpinan transaksional, budaya organisasi serta komunikasi yang baik agar kinerja dari karyawan terus meningkat. Keterbatasan penelitian ini yaitu minimnya sampel dalam perusahaan serta hanya menggunakan 3 variabel yang mempengaruhi kinerja karyawan yaitu kepemimpinan transaksional, budaya organisasi dan komunikasi.
\end{abstract}

Kata kunci: kinerja karyawan; kepemimpinan transaksional; budaya organisasi; komunikasi

\begin{abstract}
Ability of leaders in low transactional leadership styles, and unclear organizational culture Difficult to determine by employees, and communication between employees or leaders with employees who are less able to create weak performance of the company. Weakening company performance will have an impact on the achievement of these companies and companies. This study aims to determine the effect of transactional, cultural, and communication on the performance of CV Nusa Kampial employees. This research was conducted at CV Nusa Kampal with 35 employees. Data collection is done by interview method and questionnaire distribution. Data analysis using classical assumption test, multiple linear regression, $f$ test, $r$ square and t test. The results showed that transactional leadership had a significant positive effect on employee performance. Organizational culture had a significant positive effect on employee performance. Stakeholders can improve leadership leadership, organizational culture and good communication so that employee performance continues to increase. The limitations of this study are the lack of samples in the company and only use 3 variables that affect employees, namely transactional leadership, organizational culture and communication. Keywords: employee performance; transactional leadership; organizational culture; communication
\end{abstract}




\section{PENDAHULUAN}

Tenaga kerja merupakan salah satu faktor utama yang harus di perhatikan oleh perusahaan dalam mencapai suatu tujuan. Dalam hal ini perusahaan dituntut untuk bisa mengelola dan memanfaatkan sumber daya secara terencana. Pengelolaan ini dimaksud untuk mencapai kinerja karyawan yang sangat tinggi terutama untuk meningkatkan kinerja perusahaan secara keseluruhan. Sehingga untuk mencapai semua itu maka perlu suatu sumber daya manusia yang memiliki kinerja yang baik. Zameer et al. (2014) menyatakan bahwa kinerja karyawan merupakan seberapa banyak seorang karyawan memberikan kontribusi kepada perusahaan meliputi kuantitas output, kualitas output, jangka waktu, kehadiran ditempat kerja dan sikap kooperatif. Kinerja seseorang yang baik dapat dilihat dari hasil kerjanya yang telah sesuai dengan standar kinerja organisasi dan dapat mencapai tujuan organisasi atau perusahaan tersebut. Organisasi yang baik dapat dilihat dari kemampuan sumber daya manusia yang dimilikinya, jika kemampuan sumber daya manusianya meningkat maka akan terciptanya organisasi atau perusahaan yang simtemnya berjalan dengan baik.

Kinerja karyawan yang meningkat akan berdampak pada kemajuan perusahaan, dimana perusahaan dapat bertahan dalam ketatnya suatu persaingan dalam lingkungan bisnis yang tidak stabil. Hasibuan (2009:121) menyatakan bahwa kinerja merupakan suatu hasil kerja karyawan yang digunakan untuk menilai karyawan atau organisasi tersebut, dengan kinerja yang baik maka tujuan perusahaan akan terwujud. Meningkatkan kinerja seseorang memang tidak mudah dikarenakan banyak faktor yang dapat mempengaruhi tinggi rendahnya kinerja seseorang. Dalam penelitian ini adapun beberapa faktor yang dapat digunakan untuk meningkatkan kinerja diantaranya adalah kepemimpinan transaksioanal, komunikasi, dan budaya organisasi.

Kepemimpinan transaksional sangat berperan penting di dalam suatu organisasi karena dengan adanya gaya kepemimpinan transaksional, pemimpin dapat melakukan suatu pertukaran dengan pengikut yang dirancang untuk memberikan manfaat bagi keduanya. Bass et al. (2003) menyatakan kepemimpinan transaksional merupakan suatu gaya kepemimpinan dimana terjadi suatu proses pertukaran antara atasan dan bawahan seperti bawahannya dapat membantu mengidentifikasikan sesuatu yang harus dilakukan untuk mencapai hasil yang diharapkan bersama sehingga bawahan akan diberi imbalan karena kinerjanya yang sudah baik. Ada beberapa penelitian terdahulu telah menguji hubungan antara kepemimpinan transaksional dengan kinerja karyawan, antara lain Jacqueline et al. (2011), Bass et al. (2003), Hayward (2005). Hasil penelitiannya menunjukan bahwa pengaruh kepemimpinan transaksional dengan kinerja karyawan menunjukan hubungan positif dan signifikan.

Robbins (2015) menyatakan budaya organisasi merupakan berbagai system yang dibuat untuk para anggotanya sehingga dapat membedakan antara suatu organisasi dengan organisasi lain. Beberapa penelitian terdahulu telah menguji hubungan antara budaya organisasi dengan kinerja karyawan, antara lain Brahmasari \& Siregar (2009), Arimbawa \& Dewi (2013), Aristayudha \& Netra (2013). Hasil penelitiannya menunjukan bahwa pengaruh budaya organisasi dengan kinerja karyawan menunjukan hubungan positif dan signifikan. 
Wahyudi (2013) menyatakan bahwa komunikasi adalah proses dalam menyampaikan ide dan informasi untuk orang lain sehingga seseorang itu mengerti dan dapat mengarah pada pencapaian tujuan. Wiguna (2015) menyatakan keterampilan komunikasi dapat menunjukan suatu hal yang membuat hasi kerja terlihat sangat baik. Beberapa peneliti telah menguji hubungan antara komunikasi dengan kinerja karyawan, antara lain Ardiansyah, (2016), Wiguna (2015), Brahmasari \& Siregar (2009). Hasil penelitiannya menunjukan bahwa pengaruh komunikasi dengan kinerja karyawan menunjukan hubungan positif dan signifikan.

CV Nusa Kampial adalah perusahaan yang bergerak di bidang retail dan supplier bahan bangunan. Perusahaan ini berdiri pada tahun 1993 dan berlokasi di Nusa Dua, Bali. Perusahaan ini awalnya menjual kerajinan kayu, kemudian di tahun 1996 perusahaan ini berkembang dan menjadi perusahaan yang menjual segala peralatan bangunan. Berdasarkan wawancara yang dilakukan pada manajer mengenai kinerja karyawan di CV Nusa Kampial, manajer menjelaskan bahwa adanya suatu masalah yang sering terjadi seperti karyawan tidak dapat menyelesaikan tugasnya tepat waktu sesuai dengan target yang telah ditetapkan serta beberapa karyawan masih sering datang terlambat ke kantor.

Tujuan penelitian ini untuk menganalisis pengaruh kepemimpinan transaksional terhadap kinerja karyawan, menganalisis pengaruh budaya organisasi terhadap kinerja karyawan, dan menganalisis pengaruh komunikasi terhadap kinerja karyawan.

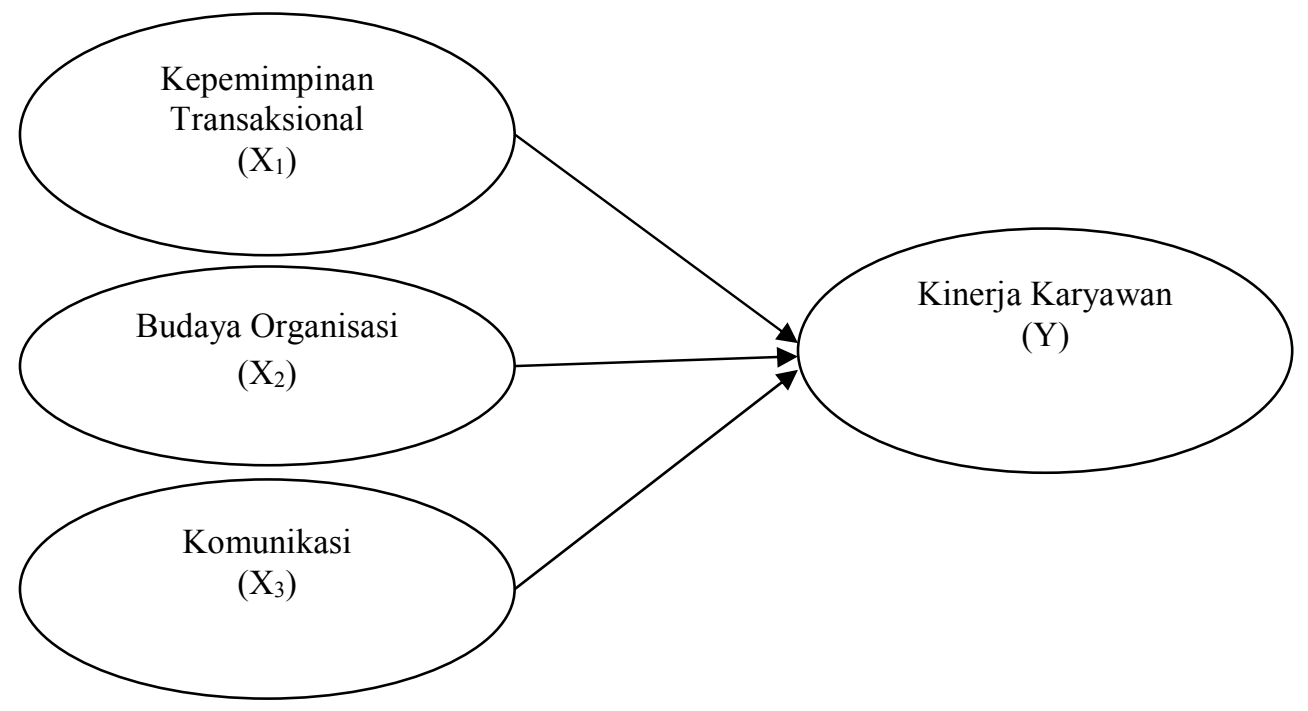

Gambar 1. Kerangka Penelitian

Teori yang melandasi penelitian ini adalah Teori pertukaran (The Social Exchange Theory). Saqib (2014) menyatakan bahwa ketika organisasi mengurus karyawan, maka ada hubungan pertukaran sosial yang menjanjikan untuk meningkatkan kinerja. Karyawan akan merasa memiliki kewajiban untuk melakukan timbal balik kepada perusahaan ketika karyawan menerima emosional sosial dan sumber daya ekonomi dari perusahaan. Karyawan yang diberdayakan 
dan diberi pelatihan maka karyawan tersebut akan mendedikasikan tenaga, perasaan,dan sumber daya kongnitif mereka untuk kinerja yang lebih baik.

Fung et al. (2012) menyatakan bahwa teori pertukaran sosial merupakan pandangan karyawan ketika mereka telah diperlakukan dengan baik oleh organisasi, mereka akan cenderung untuk bersikap dan berperilaku lebih positif terhadap organisasi. Serim et al. (2014) mengemukakan bahwa hubungan di tempat kerja memiliki unsur-unsur dari teori pertukaran sosial.

Seorang pemimpin perusahan yang mengetahui keinginan karyawan dan dapat menjelaskan apa yang akan diperoleh jika hasil kerjanya sesuai dengan harapan seperti memberikan imbalan yang sebanding dengan kinerjanya, maka karyawan akan berusaha untuk menunjukan kinerjanya yg baik secara maksimal. Proses timbal balik yang baik dan sesuai antara pemimpin dan karyawan akan menimbulkan komunikasi diantara keduanya lebih lancar dan dengan komunikasi yg lancar seluruh karyawan dapat lebih memahami nilai - nilai yang ada dalam perusahaan atau budaya organisasi yang dimiliki perusahan akan mulai tumbuh. Semua itu tentu akan berdampak kepada kinerja karyawan yang semakin meningkat dilihat dari hasil kerja para karyawannya. Jadi Teori Pertukan Sosial ini dapat melandasi penelitian ini, dimana pemimpin dengan karyawan maupun karyawan dengan perusahaan saling menjaga keseimbangan pertukaran sosial satu sama lainnya.

Hasibuan (2009:121) menyatakan bahwa kinerja merupakan suatu hasil kerja karyawan yang digunakan untuk menilai karyawan atau organisasi tersebut. Mangkunegara (2009) menyatakan bahwa kinerja merupakan prestasi kerja atau output kerja, yang dinilai dari kualitas maupun kuantitasnya dalam melakukan tugas yang diberikan sesuai dengan tanggung jawabnya. Hasil kerja yang baik dilihat dari segi kualitas maupun kuantitas pekerjaan dan dapat dipertanggung jawabkan sesuai dengan prestasi kerja yang dihasilkan oleh karyawan sesuai dengan peran didalam organisasi atau perusahaan itulah yang biasanya disebut dengan kinerja.

Thao \& Hwang (2015) menyatakan ada faktor-faktor yang dapat mempengaruhi kinerja karyawan yaitu 1) kepemimpinan adalah suatu proses dimana seorang individu mempengaruhi sekelompok individu untuk mencapai tujuan bersama (Northouse, 2007). 2) Coaching, cara yang dapat meningkatkan kinerja. Dengan cara komunikasi dua arah dimana pelatih dapat mengidentifikasi apa yang perlu ditingkatkan dan bagaimana cara untuk meningkatkannya Champathes (2006). 3) Participation, Chen \& Tjosvold, (2006) menyatakan partisipasi merupakan suatu perlibatkan karyawan dalam proses mengambil keputusan dimana karyawan merasa memiliki kesempatan untuk memecahkan masalah dan dapat mempengaruhi keputusan organisasi. Dampak keseluruhan dari partisipasi tersebut adalah meningkatnya kinerja karyawan. 4) Motivation, Green (2000) menyatakan bahwa motivasi sangat penting untuk meningkatkan kinerja karyawan. Jadi, manajemen harus bisa memotivasi karyawan agar karyawan tetap produktif dalam bekerja.

Wirawan (2009) menyatakan bahwa kinerja karyawan dapat diukur dengan 9 indikator yaitu 1) Kuantitas hasil kerja, persepsi responden tentang penyelesaian pekerjaan dengan penuh rasa tanggung jawab dalam pencapaian hasil yang 
seoptimal mungkin 2) Kualitas hasil kerja, persepsi responden tentang penyelesaian pekerjaan sesuai dengan standar mutu yang ditetapkan oleh perusahaan. 3) Efisiensi dalam melaksanakan pekerjaan, persepsi responden tentang penyelesaian pekerjaan sesuai dengan target waktu yang ditentukan. 4) Disiplin kerja merupakan persepsi responden tentang kehadiran yang tepat waktu sesuai dengan jadwal yang ditentukan di tempat kerja. 5) Inisiatif merupakan persepsi responden tentang penyelesaian pekerjaan dengan berinisiatif tanpa menunggu perintah dari pemimpin. 6) Ketelitian merupakan persepsi responden tentang ketelitian dalam menyelesaikan pekerjaan. 7) Kepemimpinan merupakan persepsi responden tentang mematuhi perintah dari atasan. 8) Kejujuran merupakan persepsi responden tentang kejujuran dalam mengerjakan pekerjaan. 9) Kreativitas merupakan persepsi responden tentang memberikan gagasan yang inovatif untuk pekerjaan di kantor.

Robbins (2009) menyatakan bahwa kepemimpinan transaksional merupakan pemimpin yang dapat membimbing dan memotivasi para bawahannya untuk mencapai tujuan yang telah sesuai dengan tugas dan kewajiban mereka. Sumarni (2010) menyatakan kepemimpinan transaksional adalah pemimpin organisasi yang dapat mencapai tujuan dengan cara lebih efisien dengan memberikan imbalan (rewards) yang sesuai dengan kemampuan karyawan dalam menyelesaikan pekerjaannya.

Dapat disimpulkan bahwa kepemimpinan transaksional merupakan suatu gaya kepemimpinan dimana terjadi suatu proses pertukaran antara atasan dan bawahan seperti bawahannya dapat membantu mengidentifikasikan sesuatu yang harus dilakukan untuk mencapai hasil yang diharapkan bersama sehingga bawahan akan diberi imbalan karena kinerjanya yang sudah baik. Sumarni (2010) menyatakan terdapat empat indikator yang mempengaruhi kepemimpinan transaksional yaitu 1) Tingkat kepercayaan merupakan persepsi responden tentang tingkat kepercayaan terhadap kinerja pemimpin. 2) Motivasi pimpinan merupakan persepsi responden tentang motivasi yang diberikan pimpinan dalam menyelesaikan pekerjaan. 3) Rewards merupakan persepsi responden tentang pemimpin memberi penghargaan atas prestasi kerja 4) Komunikasi pimpinan merupakan persepsi responden tentang penyampaian tugas dengan baik dari pimpinan sesuai dengan job base.

Robbins (2015) menyatakan budaya organisasi merupakan berbagai system yang dibuat untuk para anggotanya sehingga dapat membedakan antara suatu organisasi dengan organisasi lain. Belias \& Koustelios (2014) budaya organisasi adalah suatu pemikiran yang mendasar untuk memecahkan suatu masalah baik masalah secara internal maupun eksternal organisasi. Diputri (2016) menyatakan bahwa pemimpin harus dapat menanamkan budaya atau kebiasaan organisasi yang baik untuk mencerminkan suatu identitas organisasi tersebut, membentuknya budaya itu secara tepat dengan strategi yang kuat untuk menanamkan perilaku ini di seluruh organisasi.

Cancerina (2013) menyatakan budaya organisasi yang terlihat nyata dan kuat dalam suatu perusahaan maka akan berdampak pada karyawan dalam motivasinya untuk menyelesaikan suatu pekerjaan. Matei (2015) menyatakan budaya organisasi adalah suatu nilai-nilai, keyakinan, harapan, aspirasi dan 
perilaku yang memiliki cirri khas yang menonjol dan mampu mempengaruhi fungsi dan penampilannya secara langsung maupun tidak langsung. Indikator pada variabel budaya organisasi Brahmasari \& Siregar (2009) yaitu 1) Tujuan Perusahaan merupakan persepsi responden tentang memahami tujuan dari perusahaan. 2) Konsensus merupakan persepsi responden tentang aspirasi yang dapat disampaikan secara langsung terkait kebijakan perusahaan. 3) Keunggulan, merupakan persepsi responden tentang penerapan nilai-nilai yang ada di dalam perusahaan. 4) Kesatuan merupakan persepsi responden tentang pemberian reward dari perusahaan berdasarkan atas kinerja karyawan. 5) Prestasi merupakan persepsi responden tentang perhatian pimpinan terhadap kinerja setiap karyawannya. 6) Keakraban merupakan persepsi responden tentang komunikasi antar karyawan terjalin dengan baik di perusahaan. 7) Integrasi merupakan persepsi responden tentang bekerjasama untuk mencapai tujuan perusahaan.

Wahyudi (2013) menyatakan bahwa komunikasi adalah proses dalam menyampaikan ide dan informasi untuk orang lain sehingga seseorang itu mengerti dan dapat mengarah pada pencapaian tujuan. Wiguna (2015) menyatakan keterampilan komunikasi dapat menunjukan suatu hal yang membuat hasi kerja terlihat sangat baik. Memiliki keterampilan komunikasi yang baik merupakan nilai tambah pada diri sehingga dapat mencapai kemajuan cepat dalam karir. Karademđr et al. (2014) juga menyatakan dengan komunikasi yang baik, seluruh karyawan di perusahaan dapat saling mengerti dengan sesama rekan kerja mereka maupun dengan atasannya sehingga terciptanya lingkungan kerja yang nyaman.

Dapat disimpulkan bahwa komunikasi adalah aktivitas yang menyebabkan orang lain menginterpretasikan suatu ide, berdasarkan pendapat tersebut maka komunikasi dapat diartikan sebagai proses pemindahan suatu informasi, ide, pengertian dari seseorang kepada dengan harapan orang lain tersebut dapat menginterpretasikannya sesuai dengan tujuan yang dimaksud. Indikator pada variabel komunikasi (Mangkunegara, 2004:148) antara lain 1) Pemahaman merupakan persepsi responden tentang pimpinan melakukan diskusi dengan karyawan. 2) Kesenangan merupakan persepsi responden tentang pimpinan memberikan semangat kepada karyawan. 3) Pengaruh pada sikap merupakan persepsi responden tentang informasi mengenai aktifitas karyawan disampaikan dengan baik. 4) Hubungan yang makin baik merupakan persepsi responden tentang tegur sapa antar karyawan dengan pimpinan terjalin dengan baik. 5) Tindakan merupakan persepsi responden tentang pimpinan menyampaikan tugas yang sesuai dengan tanggung jawab karyawan

Jacqueline et al. (2011) menyatakan seluruh karyawan dapat ikut serta memberikan kontribusinya terhadap perusahaan karena dapat mengaruh dari gaya kepemimpinan transaksional. Hasil penelitian Bass et al. (2003) menyatakan kepemimpinan transaksional sangat mempengaruhi kinerja seorang karyawan didalam bekerja. Pernyataan ini juga didukung oleh Hayward (2005), Mahdinezhad et al. (2013), Bagus (2018) menyatakan bahwa kepemimpinan transaksional merupakann salah satu faktor yang dapat meningkatkan kinerja karyawan. Rumusan hipotesis penelitian dari beberapa sumber di atas dapat dinyatakan sebagai berikut 
$\mathrm{H}_{1}$ : kepemimpinan transaksional berpengaruh positif dan signifikan terhadap kinerja karyawan.

Brahmasari \& Siregar (2009)menyatakan bahwa budaya organisasi berpengaruh positif terhadap kinerja karyawan. Hasil penelitian Arimbawa \& Dewi (2013) juga menyatakan bahwa variabel budaya organisasi berpengaruh positif signifikan terhadap kinerja karyawan. Pernyataan ini juga didukung oleh Mohamed and Abukar (2013), Wanjiku \& Lumwagi (2014), Aristayudha \& Netra (2013)yang menyatakan bahwa budaya organisasi berpengaruh positif dan signifikan terhadap kinerja karyawan. Rumusan hipotesis penelitian dari beberapa sumber di atas dapat dinyatakan sebagai berikut

$\mathrm{H}_{2}$ : budaya organisasi berpengaruh positif dan signifikan terhadap kinerja karyawan.

Ardiansyah (2016)menyatakan bahwa komunikasi berpengaruh positif dan signifikan terhadap kinerja karyawan. Hasil penelitian Wiguna (2015) juga menyatakan komunikasi secara simultan berpengaruh signifikan terhadap kinerja karyawan. Begitu juga yang dilakukan oleh Brahmasari \& Siregar (2009), Neves \& Eisenberger (2012), dan Putri (2017) menyatakan bahwa komunikasi berpengaruh positif terhadap kinerja karyawan. Rumusan hipotesis penelitian dari beberapa sumber di atas dapat dinyatakan sebagai berikut

$\mathrm{H}_{3}$ : komunikasi berpengaruh positif dan signifikan terhadap kinerja karyawan

\section{METODE PENELITIAN}

Penelitian ini dilakukan pada perusahaan CV Nusa Kampial yang terletak di Jalan Dharmawangsa 6-A, Nusa Dua, Bali, karena di CV Nusa Kampial terdapat masalah pada Kinerja karyawannya. Populasi penelitian ini adalah seluruh karyawan CV Nusa Kampial yang berjumlah 35 orang.

Jenis data kuantitatif penelitian ini adalah hasil survei dan wawancara yang dilakukan dengan manajer perusahaan dan data kualitatifnya adalah pernyataanpernyataan yang diajukan dalam kuisioner.

Penelitian ini menggunakan kuisioner sebagai instrumen penelitian, agar mengetahui apakah kuisioner layak atau tidak untuk dijadikan sebagai instrumen penelitian maka terlebih dahulu dilakukannya uji validitas dan uji reliabilitas. Jadi untuk memenuhi syarat validitas butir pernyataan dalam penelitian harus memiliki koefisien korelasi lebih dari 0,3. Variabel dikatakan reliable jika memberikan nilai Cronbach's Alpha lebih dari 0,6.

Teknik analisis yang digunakan pada penelitian ini berupa uji asumsi klasik yaitu uji normalitas, uji heteroskedastisitas, dan uji multikolinieritas, regresi linier berganda, uji F, R Square dan uji T. Metode regresi linier berganda dalam penelitian ini digunakan untuk mengetahui pengaruh anatara variabel yang ada dalam penelitian ini seperti variabel kepemimpinan transaksional $\left(\mathrm{X}_{1}\right)$, budaya organisasi $\left(\mathrm{X}_{2}\right)$, komunikasi $\left(\mathrm{X}_{3}\right)$ dan kinerja karyawan $(\mathrm{Y})$. Sistem komputer berupa SPSS. 21 digunakan dalam uji metode penelitian ini.

Metode regresi linier berganda digunakan dalam penelitian ini untuk mengetahui pengaruh kepemimpinan transaksional $\left(\mathrm{X}_{1}\right)$, budaya organisasi $\left(\mathrm{X}_{2}\right)$, komunikasi $\left(\mathrm{X}_{3}\right)$ dan kinerja karyawan $(\mathrm{Y})$. Metode ini diuji menggunakan sistem 
komputer berupa SPSS.21. Pengaruh variabel independen terhadap variabel dependen diuji dengan tingkat kepercayaan $95 \%$ atau $\alpha=5 \%$. Model regresi yang digunakan adalah sebagai berikut:

$$
Y=\alpha+\beta_{1} X_{1}+\beta_{2} X_{2}+\beta_{3} X_{3}+\varepsilon
$$

Keterangan:

$$
\begin{array}{ll}
\mathrm{Y} & =\text { Kinerja Karyawan } \\
\mathrm{X}_{1} & =\text { Kepemimpinan Transaksional } \\
\mathrm{X}_{2} & =\text { Budaya Organisasi } \\
\mathrm{X}_{3} & =\text { Komunikasi } \\
\alpha & =\text { Konstanta } \\
\beta_{1} & =\text { Koefisien regresi kepemimpinan transaksional } \\
\beta_{2} & =\text { Koefisien regresi budaya organisasi } \\
\beta_{2} & =\text { Koefisien regresi komunikasi } \\
\varepsilon & =\text { eror }
\end{array}
$$

\section{HASIL DAN PEMBAHASAN}

Tabel 1.

Karakteristik Responden Berdasarkan Jenis Kelamin di CV Nusa Kampial

\begin{tabular}{llll}
\hline No & Jenis Kelamin & Jumlah Orang & Persentase (\%) \\
\hline 1. & Laki-Laki & 28 & 80,00 \\
2. & Perempuan & 7 & 20,00 \\
& Total & 35 & 100 \\
\hline
\end{tabular}

Sumber : Data primer diolah, 2018

Tabel 1. menunjukkan bahwa pesentase terbesar sebesar 80,00 persen adalah laki-laki sebanyak 28 orang, sedangkan sisanya perempuan sebanyak 7 orang dengan persentase 20,00 persen. Artinya sebagian besar karyawan CV Nusa Kampial mempekerjakan tenaga laki-laki.

Tabel 2.

Karakteristik Responden Berdasarkan Usia di CV Nusa Kampial

\begin{tabular}{llll}
\hline No & Usia & Jumlah Orang & Persentase (\%) \\
\hline 1 & $21-30$ Tahun & 15 & 42,86 \\
2 & $31-40$ Tahun & 10 & 28,57 \\
3 & $41-50$ Tahun & 6 & 17,14 \\
4 & $51-60$ Tahun & 4 & 11,43 \\
& Total & 35 & 100 \\
\hline
\end{tabular}

Sumber : Data primer diolah, 2018

Tabel 2. menunjukkan bahwa persentase terbesar yaitu 42,86 persen untuk kelompok usia 21-30 tahun. Hal ini menunjukkan bahwa karyawan CV Nusa Kampial didominasi oleh usia 21-30 tahun yang berada pada usia yang masih mampu menghasilkan kinerja yang optimal. 
Tabel 3.

Karakteristik Responden Berdasarkan Pendidikan Terakhir di CV Nusa Kampial

\begin{tabular}{llll}
\hline No & Pendidikan & Jumlah Orang & Persentase (\%) \\
\hline 1 & SMA & 20 & 57,14 \\
2 & DIPLOMA & 11 & 31,43 \\
3 & S1 & 3 & 8,57 \\
4 & S2 & 1 & 2,86 \\
& Total & 35 & 100 \\
\hline
\end{tabular}

Sumber : Data primer diolah, 2018

Tabel 3. menunjukkan sebagian besar responden berdasarkan pendidikan terakhir adalah SMA sebanyak 20 orang dengan persentase sebesar 57,14 persen, sedangkan kelompok pendidikan terakhir paling rendah yang dimiliki oleh responden adalah S2 yaitu hanya 1 orang dengan persentase sebesar 2,86 persen. Hal ini menunjukkan bahwa karyawan CV Nusa Kampial didominasi oleh pendidikan terakhir SMA.

Tabel 4.

Karakteristik Responden Berdasarkan Lama Bekerja Karyawan CV Nusa

Kampial

\begin{tabular}{llll}
\hline No & Masa Kerja & Jumlah Orang & Persentase \%) \\
\hline 1 & 1-3 Tahun & 9 & 25,71 \\
2 & 4-6 Tahun & 19 & 54,29 \\
3 & 7-9 Tahun & 7 & 20,00 \\
& Total & 35 & 100 \\
\hline
\end{tabular}

Sumber : Data primer diolah, 2018

Tabel 4. menunjukkan bahwa masa kerja responden selama 4-6 tahun memiliki persentase tertinggi sebesar 54,29 persen dapat dikatakan bahwa responden yang sudah lama bekerja lebih banyak memiliki pengalaman sehingga handal dalam bekerja dan akan memiliki kesempatan untuk pengembangan karirnya.

Tabel 5.

Hasil Uji Validitas Instrumen Penelitian

\begin{tabular}{ccc}
\hline Variabel & Instrumen & Koefisien Korelasi \\
\hline Kinerja karyawan $(\mathrm{Y})$ & $\mathrm{Y}_{1}$ & 0,798 \\
& $\mathrm{Y}_{2}$ & 0,561 \\
$\mathrm{Y}_{3}$ & 0,781 \\
$\mathrm{Y}_{4}$ & 0,798 \\
& $\mathrm{Y}_{5}$ & 0,659 \\
& $\mathrm{Y}_{6}$ & 0,792 \\
& $\mathrm{Y}_{7}$ & 0,831 \\
& $\mathrm{Y}_{8}$ & 0,746 \\
& $\mathrm{Y}_{9}$ & 0,708 \\
\hline
\end{tabular}

Bersambung... 
Lanjutan Tabel 5.

\begin{tabular}{lcc}
\hline \multicolumn{1}{c}{ Variabel } & Instrumen & Koefisien Korelasi \\
\hline Kepemimpinan & $\mathrm{X}_{1.1}$ & 0,878 \\
transaksional $\left(\mathrm{X}_{1}\right)$ & $\mathrm{X}_{1.2}$ & 0,909 \\
& $\mathrm{X}_{1.3}$ & 0,571 \\
Budaya organisasi $\left(\mathrm{X}_{2}\right)$ & $\mathrm{X}_{1.4}$ & 0,856 \\
& $\mathrm{X}_{2.1}$ & 0,840 \\
& $\mathrm{X}_{2.2}$ & 0,839 \\
& $\mathrm{X}_{2.3}$ & 0,780 \\
& $\mathrm{X}_{2.4}$ & 0,836 \\
& $\mathrm{X}_{2.5}$ & 0,805 \\
$\mathrm{X}_{2.6}$ & 0,794 \\
& $\mathrm{X}_{2.7}$ & 0,704 \\
& $\mathrm{X}_{3.1}$ & 0,723 \\
& $\mathrm{X}_{3.2}$ & 0,821 \\
& $\mathrm{X}_{3.3}$ & 0,860 \\
& $\mathrm{X}_{3.4}$ & 0,759 \\
& $\mathrm{X}_{3.5}$ & 0,829
\end{tabular}

Sumber : Data primer diolah, 2018

Tabel 5. menunjukkan bahwa seluruh indikator dalam 4 variabel tersebut memiliki nilai Koefisien Korelasi yang lebih besar dari 0,3 sehingga butir-butir pernyataan tersebut dikatakan valid dan layak digunakan sebagai instrumen penelitian.

Tabel 6.

Hasil Uji Reliabilitas

\begin{tabular}{lcc}
\hline \multicolumn{1}{c}{ Variabel } & Alpha Cronbach & Keterangan \\
\hline Kinerja karyawan $(\mathrm{Y})$ & 0,896 & Reliabel \\
Kepemimpinan transaksional $\left(\mathrm{X}_{1}\right)$ & 0,821 & Reliabel \\
Budaya organisasi $\left(\mathrm{X}_{2}\right)$ & 0,906 & Reliabel \\
Komunikasi $\left(\mathrm{X}_{3}\right)$ & 0,856 & Reliabel \\
\hline
\end{tabular}

Sumber : Data primer diolah, 2018

Tabel 6. menunjukkan bahwa seluruh instrumen penelitian memiliki koefisien Alpha Cronbach lebih besar dari 0,6. Artinya seluruh variabel telah memenuhi syarat reliabilitas atau kehandalan sehingga dapat digunakan untuk melakukan penelitian. 
Tabel 7.

Deskripsi Jawaban Responden Mengenai Variabel Kinerja Karyawan

\begin{tabular}{|c|c|c|c|c|c|c|c|c|}
\hline \multirow{2}{*}{ Pernyataan Kinerja Karyawan } & \multicolumn{5}{|c|}{$\begin{array}{l}\text { Frekuensi Jawaban } \\
\text { Responden }\end{array}$} & \multirow{2}{*}{$\begin{array}{l}\text { Total } \\
\text { skor }\end{array}$} & \multirow{2}{*}{$\begin{array}{l}\text { Rata- } \\
\text { rata }\end{array}$} & \multirow[t]{2}{*}{ Ket } \\
\hline & 1 & 2 & 3 & 4 & 5 & & & \\
\hline $\begin{array}{l}\text { Saya berusaha untuk menyelesaikan } \\
\text { pekerjaan dengan penuh rasa tanggung } \\
\text { jawab untuk mencapai hasil yang } \\
\text { maksimal. }\end{array}$ & 0 & 0 & 4 & 18 & 13 & 149 & 4.26 & $\begin{array}{l}\text { Sangat } \\
\text { Baik }\end{array}$ \\
\hline $\begin{array}{l}\text { Saya bekerja sesuai dengan standar mutu } \\
\text { yang telah ditetapkan oleh perusahaan. }\end{array}$ & 0 & 0 & 1 & 17 & 17 & 156 & 4.46 & $\begin{array}{l}\text { Sangat } \\
\text { Baik }\end{array}$ \\
\hline $\begin{array}{l}\text { Saya berusaha menyelesaikan pekerjaan } \\
\text { yang diberikan sesuai dengan target } \\
\text { waktu yang telah ditentukan. }\end{array}$ & 0 & 0 & 1 & 18 & 16 & 155 & 4.43 & $\begin{array}{l}\text { Sangat } \\
\text { Baik }\end{array}$ \\
\hline $\begin{array}{l}\text { Saya hadir tepat waktu sesuai dengan } \\
\text { jadwal yang sudah ditetapkan di tempat } \\
\text { kerja. }\end{array}$ & 0 & 0 & 1 & 16 & 18 & 157 & 4.49 & $\begin{array}{l}\text { Sangat } \\
\text { Baik }\end{array}$ \\
\hline $\begin{array}{l}\text { Dalam menyelesaikan pekerjaan saya } \\
\text { berinisiatif tanpa menunggu perintah dari } \\
\text { pemimpin. }\end{array}$ & 0 & 0 & 1 & 19 & 15 & 154 & 4.40 & $\begin{array}{l}\text { Sangat } \\
\text { Baik }\end{array}$ \\
\hline Saya teliti dalam bekerja. & 0 & 0 & 1 & 17 & 17 & 156 & 4.46 & $\begin{array}{l}\text { Sangat } \\
\text { Baik }\end{array}$ \\
\hline Saya mematuhi perintah dari atasan. & 0 & 0 & 4 & 19 & 12 & 148 & 4.23 & $\begin{array}{l}\text { Sangat } \\
\text { Baik }\end{array}$ \\
\hline Saya jujur dalam bekerja & 0 & 0 & 3 & 12 & 20 & 157 & 4.49 & $\begin{array}{l}\text { Sangat } \\
\text { Baik }\end{array}$ \\
\hline $\begin{array}{l}\text { Saya memberikan gagasan yang inovatif } \\
\text { untuk pekerjaan di kantor }\end{array}$ & 0 & 1 & 12 & 14 & 8 & 134 & 3.83 & Baik \\
\hline Rata-rata & & & & & & & 4,34 & $\begin{array}{l}\text { Sangat } \\
\text { Baik }\end{array}$ \\
\hline
\end{tabular}

Sumber : Data primer diolah, 2018

Tabel 7. menunjukkan bahwa deskripsi jawaban responden terhadap variabel kinerja karyawan sebesar 4,34 yang di golongkan dalam kriteria sangat baik. Artinya, karyawan CV Nusa Kampial rata - rata telah memiliki kinerja karyawan yang sangat baik.

Tabel 8.

Deskripsi Jawaban Responden Mengenai Kepemimpinan Transaksional

\begin{tabular}{|c|c|c|c|c|c|c|c|c|}
\hline \multirow{2}{*}{$\begin{array}{l}\text { Pernyataan Kepemimpinan } \\
\text { Transaksional }\end{array}$} & \multicolumn{5}{|c|}{$\begin{array}{c}\text { Frekuensi Jawaban } \\
\text { Responden }\end{array}$} & \multirow{2}{*}{$\begin{array}{l}\text { Total } \\
\text { skor }\end{array}$} & \multirow{2}{*}{$\begin{array}{l}\text { Rata- } \\
\text { rata }\end{array}$} & \multirow[t]{2}{*}{ Ket } \\
\hline & 1 & 2 & 3 & 4 & 5 & & & \\
\hline $\begin{array}{l}\text { Saya memiliki tingkat kepercayaan } \\
\text { yang tinggi terhadap kinerja pemipin. }\end{array}$ & 0 & 0 & 1 & 22 & 12 & 151 & 4.31 & $\begin{array}{l}\text { Sangat } \\
\text { Baik }\end{array}$ \\
\hline $\begin{array}{l}\text { Saya menerima motivasi dari pimpinan } \\
\text { dalam menyelesaikan pekerjaan. }\end{array}$ & 0 & 0 & 3 & 21 & 11 & 148 & 4.23 & $\begin{array}{l}\text { Sangat } \\
\text { Baik }\end{array}$ \\
\hline $\begin{array}{l}\text { Saya diberikan penghargaan atas } \\
\text { prestasi kerja. }\end{array}$ & 0 & 0 & 4 & 19 & 12 & 148 & 4.23 & $\begin{array}{l}\text { Sangat } \\
\text { Baik }\end{array}$ \\
\hline $\begin{array}{l}\text { Saya menerima penyampaian tugas } \\
\text { dengan baik dari pimpinan sesuai } \\
\text { dengan job base. }\end{array}$ & 0 & 0 & 3 & 22 & 10 & 147 & 4.20 & Baik \\
\hline Rata-rata & & & & & & & 4,24 & $\begin{array}{l}\text { Sangat } \\
\text { Baik }\end{array}$ \\
\hline
\end{tabular}

Sumber : Data primer diolah, 2018 
Tabel 8. menunjukkan bahwa deskripsi jawaban responden terhadap variabel kepemimpinan transaksional sebesar 4,24 yang di golongkan dalam kriteria sangat baik. Artinya, karyawan CV Nusa Kampial telah merasakan kepemimpinan transaksional dari pemimpinnya dengan sangat baik

Tabel 9.

Deskripsi Jawaban Responden Mengenai Variabel Budaya Organisasi

\begin{tabular}{|c|c|c|c|c|c|c|c|c|}
\hline \multirow{2}{*}{ Pernyataan Budaya Organisasi } & \multicolumn{5}{|c|}{$\begin{array}{l}\text { Frekuensi Jawaban } \\
\text { Responden }\end{array}$} & \multirow{2}{*}{$\begin{array}{l}\text { Total } \\
\text { skor }\end{array}$} & \multirow{2}{*}{$\begin{array}{l}\text { Rata- } \\
\text { rata }\end{array}$} & \multirow[t]{2}{*}{ Ket } \\
\hline & 1 & 2 & 3 & 4 & 5 & & & \\
\hline $\begin{array}{l}\text { Saya memahami tujuan dari } \\
\text { perusahaan. }\end{array}$ & 0 & 0 & 4 & 19 & 12 & 148 & 4.23 & $\begin{array}{l}\text { Sangat } \\
\text { Baik }\end{array}$ \\
\hline $\begin{array}{l}\text { Aspirasi setiap karyawan dapat } \\
\text { disampaikan secara langsung terkait } \\
\text { kebijakan perusahaan. }\end{array}$ & 0 & 0 & 1 & 13 & 21 & 160 & 4.57 & $\begin{array}{l}\text { Sangat } \\
\text { Baik }\end{array}$ \\
\hline $\begin{array}{l}\text { Saya selalu menerapkan nilai-nilai } \\
\text { yang ada di dalam perusahaan. }\end{array}$ & 0 & 0 & 2 & 19 & 14 & 152 & 4.34 & $\begin{array}{l}\text { Sangat } \\
\text { Baik }\end{array}$ \\
\hline $\begin{array}{l}\text { Pemberian reward dari perusahaan } \\
\text { kepada karyawan berdasarkan atas } \\
\text { kinerja karyawan. }\end{array}$ & 0 & 0 & 2 & 16 & 17 & 155 & 4.43 & $\begin{array}{l}\text { Sangat } \\
\text { Baik }\end{array}$ \\
\hline $\begin{array}{l}\text { Pimpinan memperhatikan kinerja } \\
\text { setiap karyawan. }\end{array}$ & 0 & 0 & 5 & 15 & 15 & 150 & 4.29 & $\begin{array}{l}\text { Sangat } \\
\text { Baik }\end{array}$ \\
\hline $\begin{array}{l}\text { Komunikasi antar karyawan terjalin } \\
\text { dengan baik di perusahaan. }\end{array}$ & 0 & 0 & 0 & 17 & 18 & 158 & 4.51 & $\begin{array}{l}\text { Sangat } \\
\text { Baik }\end{array}$ \\
\hline $\begin{array}{l}\text { Karyawan bekerjasama untuk } \\
\text { mencapai tujuan perusahaan. }\end{array}$ & 0 & 0 & 2 & 18 & 15 & 153 & 4.37 & Baik \\
\hline Rata-rata & & & & & & & 4,39 & $\begin{array}{l}\text { Sangat } \\
\text { Baik }\end{array}$ \\
\hline
\end{tabular}

Sumber : Data primer diolah, 2018.

Tabel 9. menunjukkan bahwa deskripsi jawaban responden terhadap variabel budaya organisasi sebesar 4,39 yang di golongkan dalam kriteria sangat baik. Artinya, karyawan CV Nusa Kampial telah merasakan budaya organisasi dalam lingkungan perusahaannya dengan sangat baik.

Tabel 10.

Deskripsi Jawaban Responden Mengenai Variabel Komunikasi

\begin{tabular}{|c|c|c|c|c|c|c|c|c|}
\hline \multirow[t]{2}{*}{ Pernyataan Komunikasi } & \multicolumn{5}{|c|}{$\begin{array}{c}\text { Frekuensi Jawaban } \\
\text { Responden }\end{array}$} & \multirow{2}{*}{$\begin{array}{l}\text { Total } \\
\text { skor }\end{array}$} & \multirow{2}{*}{$\begin{array}{l}\text { Rata } \\
- \\
\text { rata }\end{array}$} & \multirow[t]{2}{*}{ Ket } \\
\hline & 1 & 2 & 3 & 4 & 5 & & & \\
\hline $\begin{array}{l}\text { Pimpinan melakukan diskusi dengan } \\
\text { karyawan }\end{array}$ & 0 & 0 & 2 & 16 & 17 & 155 & 4.43 & $\begin{array}{l}\text { Sangat } \\
\text { Baik }\end{array}$ \\
\hline $\begin{array}{l}\text { Pimpinan memberikan semangat } \\
\text { kepada karyawan }\end{array}$ & 0 & 0 & 5 & 9 & 21 & 156 & 4.46 & $\begin{array}{l}\text { Sangat } \\
\text { Baik }\end{array}$ \\
\hline $\begin{array}{l}\text { Informasi mengenai aktifitas karyawan } \\
\text { disampaikan dengan baik }\end{array}$ & 0 & 0 & 1 & 12 & 22 & 161 & 4.60 & $\begin{array}{l}\text { Sangat } \\
\text { Baik }\end{array}$ \\
\hline $\begin{array}{l}\text { Tegur sapa antar karyawan dengan } \\
\text { pimpinan terjalin dengan baik }\end{array}$ & 0 & 0 & 6 & 12 & 17 & 151 & 4.31 & $\begin{array}{l}\text { Sangat } \\
\text { Baik }\end{array}$ \\
\hline $\begin{array}{l}\text { Pimpinan menyampaikan tugas kepada } \\
\text { karyawan sesuai dengan tanggung } \\
\text { jawab karyawannya }\end{array}$ & 0 & 0 & 1 & 12 & 22 & 161 & 4.60 & $\begin{array}{l}\text { Sangat } \\
\text { Baik }\end{array}$ \\
\hline Rata-rata & & & & & & & 4,48 & $\begin{array}{l}\text { Sangat } \\
\text { Baik }\end{array}$ \\
\hline
\end{tabular}

Sumber : Data primer diolah, 2018. 
Tabel 10. menunjukkan bahwa deskripsi jawaban responden terhadap variabel kepemimpinan transaksional sebesar 4,48 yang di golongkan dalam kriteria sangat baik. Artinya, karyawan CV Nusa Kampial telah menjalin hubungan antar karyawan dengan komunikasi yang sangat baik.

Hasil analisis data menggunakan uji asumsi klasik yaitu dengan uji normalitas, uji multikolinearitas, dan uji hesteroskedastisitas.

Tabel 11.

Hasil Uji Normalitas

\begin{tabular}{cc}
\hline & Unstandardized Residual \\
\hline $\mathrm{N}$ & 35 \\
Kolmogorov-Smirnov Z & 0,714 \\
Asymp. Sig. (2-tailed) & 0,688 \\
\hline
\end{tabular}

Sumber : Data diolah, 2018.

Tabel 11. menguji apakah data yang digunakan normal atau tidak dapat dilakukan dengan menggunakan uji Kolmogorov-Smirnov jika nilai Asymp. Sig. (2-tailed) lebih besar taraf signifikansi yang ditetapkan yaitu 5 persen $(0,05)$, maka data telah berdistribusi normal. Berdasarkan hasil analisis, diperoleh hasil sebesar 0,688 $>0,05$ yang artinya data berdistribusi normal.

Tabel 12.

Hasil Uji Multikolinearitas

\begin{tabular}{lcc}
\hline \multicolumn{1}{c}{ Model } & \multicolumn{2}{c}{ Colinearity Statistic } \\
& Tolerance & VIF \\
\hline Kepemimpinan Transaksional $\left(\mathrm{X}_{1}\right)$ & 0,474 & 2,111 \\
Budaya Organisasi $\left(\mathrm{X}_{2}\right)$ & 0,342 & 2,920 \\
Komunikasi $\left(\mathrm{X}_{3}\right)$ & 0,276 & 3,621 \\
\hline
\end{tabular}

Sumber : Data diolah, 2018.

Tabel 12. mendeteksi ada atau tidaknya multikolinearitas dalam model regresi yaitu mempunyai angka Tolerance $>0,10$ atau mempunyai nilai $\mathrm{VIF}<10$. Berdasarkan hasil analisis, dapat dilihat bahwa koefisien Tolerance semua variabel lebih besar dari 0,10 dan nilai VIF yang lebih kecil dari 10 . Hasil ini mengindikasikan bahwa tidak terdapat gejala multikolinear dari model regresi yang dibuat sehingga pada model regresi ditemukan korelasi antar variabel bebas.

Tabel 13.

Hasil Uji Heteroskedastisitas

\begin{tabular}{lllcccc}
\hline \multirow{2}{*}{ Model } & \multicolumn{2}{c}{$\begin{array}{c}\text { Unstandardized } \\
\text { Coefficients } \\
\text { Std. Error }\end{array}$} & $\begin{array}{c}\text { Standardized } \\
\text { Coefficients } \\
\text { Beta }\end{array}$ & T & Sig. \\
& \multicolumn{2}{c}{ B } & 0,157 & & 1,026 & 0,313 \\
\hline 1 & (Constant) & 0,161 & 0,048 & 0,142 & 0,574 & 0,570 \\
& Kepemimpinan Transaksional & 0,027 & 0,056 & $-0,537$ & $-1,847$ & 0,074 \\
& Budaya Organisasi & $-0,103$ & 0,055 & 0,364 & 1,126 & 0,269 \\
Komunikasi & 0,062 & \multicolumn{4}{c}{}
\end{tabular}


Tabel 13. memastikan tidak adanya perbedaan varians dari pengamatan ke pengamatan lainnya pada struktur regresi. Jika nilai Sig. lebih besar dari taraf signifikansi yang ditetapkan yaitu 5 persen $(0,05)$, maka model yang dibuat tidak mengandung gejala heteroskedastisitas. Hasil uji heterokedatisitas penelitian ini menunjukkan bahwa nilai Sig. dari variabel kepemimpinan transaksional, budaya organisasi, dan komunikasi masing-masing sebesar 0,$313 ; 0,570 ; 0,074$; dan 0,269 sudah lebih besar dari 0,05 yang berarti tidak terdapat pengaruh antara variabel bebas terhadap absolute resiudal. Dengan demikian model yang dibuat tidak mengandung gejala heteroskedastisitas.

Analisis regresi linier berganda penelitian ini diperoleh hasil yang ditunjukkan pada Tabel 14 .

Tabel 14.

Hasil Uji Analisis Regresi Linier Berganda

\begin{tabular}{lccccc}
\hline \multicolumn{1}{c}{ Model } & Unstandardized Coefficients & $\begin{array}{c}\text { Standardized } \\
\text { Coefficients }\end{array}$ & T & Sig. \\
& B & Std. Error & Beta & & \\
\hline $\begin{array}{l}\text { (constans) } \\
\text { Kepemimpinan }\end{array}$ & 0,527 & 0,269 & & 1,961 & 0,059 \\
Transaksional & 0,232 & 0,082 & 0,257 & 2,834 & 0,008 \\
$\begin{array}{l}\text { Budaya } \\
\text { Organisasi }\end{array}$ & 0,239 & 0,095 & 0,269 & 2,519 & 0,017 \\
$\begin{array}{l}\text { Komunikasi } \\
\text { R Square }\end{array}$ & 0,396 & 0,094 & 0,500 & 4,209 & 0,000 \\
$\begin{array}{l}\text { F Stastistik } \\
\text { Signifikansi }\end{array}$ & & & & & \\
\hline Sumber $:$ Data diolah, 2018. & & & &
\end{tabular}

Hasil analisis regresi linier berganda seperti yang ditunjukkan pada Tabel 14. , maka persamaan regresinya adalah sebagai berikut.

$\mathrm{Y}=0,537+0,232 \mathrm{X}_{1}+0,239 \mathrm{X}_{2}+0,396 \mathrm{X}_{3}$

Dimana :

$\mathrm{Y}=$ Kinerja Karyawan

$\mathrm{X}_{1}=$ Kepemimpinan Transaksional

$\mathrm{X}_{2}=$ Budaya Organisasi

$\mathrm{X}_{3}=$ Komunikasi

Interprestasi persamaan diatas menunjukan nilai $X_{1}=+0,232$, berarti bahwa kepemimpinan transaksional $\left(\mathrm{X}_{1}\right)$ berpengaruh positif terhadap kinerja karyawan (Y) di CV Nusa Kampial. Nilai $\mathrm{X}_{2}=+0,239$, berarti bahwa budaya organisasi $\left(\mathrm{X}_{2}\right)$ berpengaruh positif terhadap kinerja karyawan $(\mathrm{Y})$ di CV Nusa Kampial. Nilai $\mathrm{X}_{3}=+0,396$, menunjukan bahwa komunikasi $\left(\mathrm{X}_{3}\right)$ berpengaruh positif terhadap kinerja karyawan (Y) di CV Nusa Kampial dan nilai $\mathrm{R}^{2}=0.867$, yang berarti bahwa sebesar 86,7 persen variabel Kinerja karyawan (Y) dipengaruhi oleh kepemimpinan transformasional $\left(\mathrm{X}_{1}\right)$, budaya organisasi $\left(\mathrm{X}_{2}\right)$ 
dan komunikasi $\left(\mathrm{X}_{3}\right)$, sedangkan sisanya sebesar 13,3 persen dipengaruhi oleh variabel lainnya di luar model penelitian.

Tabel 15.

Uji Anova

\begin{tabular}{ccccccc}
\hline & Model & $\begin{array}{c}\text { Sum of } \\
\text { Squares }\end{array}$ & Df & $\begin{array}{c}\text { Mean } \\
\text { Square }\end{array}$ & F & Sig. \\
\hline \multirow{2}{*}{1} & Regression & 4.507 & 3 & 1.502 & 75.081 & $.000^{\mathrm{a}}$ \\
& Residual & .620 & 31 & .020 & & \\
& Total & 5.127 & 34 & & & \\
\hline
\end{tabular}

Sumber : Data diolah, 2018.

Tabel 15. menunjukkan nilai sig. $0,000<0,05$. Maka $\mathrm{H}_{0}$ ditolak pada taraf nyata $0,05\left(\mathrm{H}_{1}\right.$ diterima). Kesimpulannya, pada kelompok yang diuji memiliki perbedaan nyata (signifikansi), berarti bahwa variabel bebas yaitu kepemimpinan transaksional $\left(\mathrm{X}_{1}\right)$, budaya organisasi $\left(\mathrm{X}_{2}\right)$, dan komunikasi $\left(\mathrm{X}_{3}\right)$ berpengaruh signifikan secara serempak atau bersama-sama terhadap variabel terikat yaitu kinerja karyawan (Y).

Tabel 14. menunjukkan besarnya nilai Adjused R Square sebesar 0,867. Hal ini mengindikasikan bahwa kontribusi kepemimpinan transaksional, budaya organisasi, dan komunikasi sebesar 0,867 yang berarti besar pengaruh variabel bebas terhadap variabel terikatnya adalah $0,867 \times 100 \%=86,7 \%$, sedangkan sebesar $13,3 \%$ dijelaskan oleh faktor-faktor lainnya yang tidak diuji dalam penelitian ini.

Pengaruh kepemimpinan transaksional terhadap kinerja karyawan diperoleh nilai Sig. t 0,008 dengan nilai koefisien beta sebesar 0.257. Nilai Sig. t 0,008< 0,05 hasil ini menunjukan bahwa kepemimpinan transaksional berpengaruh positif dan signifikan terhadap kinerja karyawan. Artinya semakin baik kepemimpinan transaksional yang diberikan oleh pemimpin maka semakin kuat tingkat kinerja karyawan CV Nusa Kampial.

Hipotesis yang diajukan dan hasil penelitian yang dilakukan oleh dengan hasil penelitian yang dilakukan oleh Jacqueline et al. (2011), Bass et al. (2003), Hayward (2005), Mahdinezhad et al. (2013), Bagus (2018) telah sesuai dengan hasil penelitian ini, dimana mereka yang menyatakan bahwa kepemimpinan transaksional berpengaruh positif signifikan terhadap kinerja karyawan. Artinya gaya kepemimpinan transaksional yang diberikan kepada karyawan dapat meningkatkan tingkat kinerja karyawan.

Pengaruh budaya organisasi terhadap kinerja karyawan diperoleh nilai Sig. $t$ 0,017 dengan nilai koefisien beta sebesar 0,269. Nilai Sig. t 0,017<0,05 hasil ini mempunyai arti budaya organisasi berpengaruh positif dan signifikan terhadap kinerja karyawan. Artinya semakin baik budaya organisasi di CV Nusa Kampial maka semakin tinggi pula tingkat kinerja karyawannya.

Hipotesis yang diajukan dan hasil penelitian yang dilakukan oleh (Brahmasari \& Siregar (2009), Arimbawa \& Dewi (2013), Mohamed (2013), Wanjiku \& Lumwagi (2014), Aristayudha \& Netra (2013) telah sesuai dengan hasil penelitian ini, dimana mereka menyatakan bahwa budaya organisasi 
berpengaruh positif dan signifikan terhadap kinerja karyawan. Artinya budaya organisasi yang tinggi dapat meningkatkan tingkat kinerja karyawan.

Pengaruh komunikasi terhadap kinerja karyawan diperoleh nilai Sig. t 0,000 dengan nilai koefisien beta sebesar 0,500. Nilai Sig. t $0,000<0,05$. Hasil ini mempunyai arti komunikasi berpengaruh positif dan signifikan terhadap kinerja karyawan. Artinya komunikasi yang baik antar karyawan CV Nusa Kampial dapat meningkatkan tingkat kinerja karyawan.

Hipotesis yang diajukan dan hasil penelitian yang dilakukan oleh Ardiansyah (2016), Wiguna (2015), Brahmasari \& Siregar (2009), Neves \& Eisenberger (2012) dan Putri (2017) telah sesuai dengan hasil penelitian ini, dimana mereka yang menyatakan bahwa komunikasi berpengaruh positif dan signifikan terhadap kinerja karyawan. artinya komunikasi yang baik dapat meningkatkan tingkat kinerja karyawan.

Terdapat implikasi teoritis dan implikasi praktis dalam penelitian ini. Hasil penelitian ini secara teoritis menunjukkan bahwa kepemimpinan transaksional, budaya organisasi dan komunikasi berpengaruh positif dan signifikan terhadap kinerja karyawan. Sehingga dapat memberi dukungan empiris dan dapat dinyatakan memperkuat hasil-hasil studi terdahulu. Hasil penelitian ini secara praktis diharapkan dapat memberikan manfaat bagi pemimpin dan karyawan $\mathrm{CV}$. Nusa Kampial untuk meningkatkan kinerja karyawan mencapai tujuan bersama.

Terdapat keterbatasan dalam penelitian ini yaitu sedikitnya sampel yang digunakan dalam penelitian ini yaitu hanya sebanyak 35 karyawan atau responden, sehingga penelitian menggunakan metode sampel jenuh dimana seluruh responden yang ada dijadikan sebagai sampel yang hanya berasal dari lingkungan perusahaan CV. Nusa Kampial, sehingga hasil penelitian tidak dapat digeneralisasi pada lingkungan perusahaan lain dan hanya dapat diterapkan dilingkungan kerja CV. Nusa Kampial.

Faktor-faktor yang mempengaruhi kinerja karyawan dalam penelitian ini hanya terdiri dari tiga variabel, yaitu kepemimpinan transaksional, budaya organisasi, dan komunikasi, sedangkan masih banyak faktor lain yang mempengaruhi kinerja karyawan

\section{SIMPULAN}

Simpulan yang dapat ditarik berdasarkan hasil analisis penelitian dan hasil pembahasan yang telah dipaparkan adalah sebagai berikut.

Kepemimpinan transaksional berpengaruh positif dan signifikan terhadap kinerja karyawan. Hal ini menunjukkan semakin baik kepemimpinan transaksional maka kinerja karyawan juga akan meningkat. Budaya organisasi berpengaruh positif dan signifikan terhadap kinerja karyawan. Hal ini menunjukkan semakin baik budaya organisasi maka kinerja karyawan juga akan meningkat.

Komunikasi berpengaruh positif dan signifikan terhadap kinerja karyawan. Hal ini menunjukkan semakin baik komunikasi maka kinerja karyawan juga akan meningkat.

Saran yang dilandasi berdasarkan hasil analisis penelitian yang dapat dilihat dari deskripsi variabel penelitian dengan nilai yang paling rendah dari masing- 
masing variabel yaitu, kepemimpinan transaksional, budaya organisasi, komunikasi, dan kinerja karyawan adalah sebagai berikut.

Pemimpin harus lebih memperjelas job base masing-masing karyawan agar karyawan menerima penyampaian tugas dengan baik sesuai dengan job base-nya masing-masing. Tujuan perusahaan harus lebih diperjelas lagi agar karyawan mampu memahami tujuan perusahaan. Pimpinan dan antar sesama karyawan harus lebih sering saling bertegur sapa agar dapat menimbulkan rasa akrab dari atasan maupun bawahan serta antar sesama karyawan. Karyawan harus lebih berani memberikan gagasan yang inovatif untuk pekerjaan di kantor demi kemajuan perusahaan.

\section{REFERENSI}

Ardiansyah, D. O. (2016). Pengaruh Komunikasi Terhadap Kinerja Karyawan Dengan Dimediasi Oleh Kepuasan Kerja. Jurnal Bisnis Dan Manajemen, 3(1), 16-30. https://doi.org/10.13140/RG.2.1.5183.7283

Arimbawa, I. K. M., \& Dewi, A. . S. K. (2013). Pengaruh Budaya Organisasi, Gaya Kepemimpinan, dan Motivasi Kerja Terhadap Kinerja Karyawan Pada Hotel Jimbaran Bali. E-Jurnal Manajemen Unud, 2(12), 1693-1710. https://doi.org/10.24843/EJMUNUD.2018.v7.i07.p11

Aristayudha, A. A. N. B., \& Netra, I. G. S. K. (2013). Pengaruh Budaya Organisasi, Kepemimpinan dan Motivasi terhadap Kinerja Karyawan pada PT BPD Bali Cabang Renon. E-Jurnal Manajemen Universitas Udayana, 2(7), 831-844. https://ojs.unud.ac.id/index.php/Manajemen/article/view/5445

Bagus, I., Pratama, I., \& Dewi, A. A. S. K. (2018). Komunikasi Interpersonal Memediasi Kepemimpinan Transaksional Terhadap Kinerja Karyawan di Purnayasa Tour and Travel Bali. E-Jurnal Manajemen Unud, 7(8), 42114236. https://doi.org/10.24843/EJMUNUD.2018.v07.i08.p07

Bass, B. M., Avolio, B. J., Jung, D. I., \& Berson, Y. (2003). Predicting Unit Performance by Assessing Transformational and Transactional Leadership. Journal of Applied Psychology, 88(2), 207-218. https://doi.org/10.1037/0021-9010.88.2.207

Belias, D., \& Koustelios, A. (2014). Organizational Culture and Job Satisfaction: a review. International Review of Management and Marketing, 4(2), 132149. https://doi.org/10.1108/0885862031047313

Brahmasari, I. A., \& Siregar, P. (2009). Pengaruh Budaya Organisai, Kepemimpinan Situasional dan Pola Komunikasi terhadap Disiplin Kerja dan kinerja karyawan pada PT. Central Proteinaprima Tbk. Jurnal Aplikasi Manajemen, 7(1), 238-250. https://doi.org/10.1093/qje/qjs048

Cancerina, Y. (2013). Pengaruh Disiplin Kerja, Motivasi Finansial dan Budaya Organisasi Terhadap Prestasi Kerja Karyawan Pada CV. SINEZ. E-Jurnal Manajemen

Unud, 2(12), 1662-1681. 
https://ojs.unud.ac.id/index.php/Manajemen/article/view/6228

Champathes, M. R. (2006). Coaching For Performance Improvement: The "COACH" Model. Development and Learning in Organisations, 20(2), 1718. https://doi.org/10.1108/14777280610645886

Chen, Y. F., \& Tjosvold, D. (2006). Participative leadership by American and Chinese managers in China: The role of relationships. Journal of Management Studies, 43(8), 1727-1752. https://doi.org/10.1111/j.14676486.2006.00657.x

Diputri, N. P. I. P. (2016). Pengaruh Keadilan Organisasi, Budaya Organisasi ,Pemberdayaan Karyawan Terhadap Komitmen Organisasi Pada LPD Desa Adat Kerobokan. E-Jurnal Manajemen Unud, 5(3), 1457-1485. https://ojs.unud.ac.id/index.php/Manajemen/article/view/16230

Fung, N. S., Ahmad, A., \& Omar, Z. (2012). Work-Family Enrichment: It 's Mediating Role in the Relationships between Dispositional Factors and Job Satisfaction. International Journal of Academic Research in Business and Social Sciences, 2(11), 73-88. https://doi.org/10.3844/ajassp.2015.242.253

Green, Thad. (2000). Three Steps to Motivation Employees. HR Magazine, pp: 55-58.

Hasibuan SP. Malayu. (2009). Manajemen Sumber Daya Manusia. Edisi Revisi. Jakarta: Bumi Aksara.

Hayward, B. A. (2005). Relationship between Employee Performance, Leadership and Emotional Intelligence in A South African Parastatal Organisation. International Journal Rhades University, 48(9), 800-809. https://core.ac.uk/download/pdf/145041821.pdf

Jacqueline. M. Omuya, David M. Kungu, Leonard S. Molongo and Dedan O. Ong'anya. (2011). Effect of Team Building on The Performance of Employees in Organization Towards The Realization of Millennium Development Goals : A Survey of Selected Banks in Eldoret. International Journal of Current Research, 3(11), 049-054.

http://www.journalcra.com/?q=node/997

Karademđr, T., Karakaya, Y. E., \& Sirin, Y. (2014). Physical Educatiion Teachers' Perceptions of Organizational Culture and Communications in Educational Institutions. Journal of Physical Education and Sport, 14(4), 637-642. https://doi.org/10.7752/jpes.2014.04099

Mahdinezhad, M., Suandi, T. Bin, Silong, A. D., \& Omar, Z. B. (2013). Transformational, Transactional Leadership Styles and Job Performance of Academic Leaders. International Education Studies, 6(11), 29-34. https://doi.org/10.5539/ies.v6n11p29 
Mangkunegara, Anwar Prabu. (2009). Evaluasi Kinerja SDM. Bandung: Penerbit Refika Aditama.

Matei, C. S. (2015). Organizational Culture and Creativity's Perspectives. Euromentor Journal Studies About Education, 7(3), 40-47. http://euromentor.ucdc.ro/euromentor-vol7no-1.pdf\#page $=30$

Mohamed, A. I., Ali, A., \& Abukar, S. (2013). The Impact Of Organizational Culture On Employees Performance Of Mogadishu Universities. Education and Manajement Sciences, 4(6), 382-391. www.savap.org.pk

Neves, P., \& Eisenberger, R. (2012). Management Communication and Employee Performance: The Contribution of Perceived Organizational Support. Journal of Humman Performance, 25(5), 452-464. https://doi.org/10.1080/08959285.2012.721834

Northouse, P. G. (2007). Leadership Theory and Practice. London: Sage Publications.

Putri, L. D. P., \& Sariyathi, N. K. (2017). Pengaruh Gaya Kepemimpinan Transformasional, Kerjasama Tim Dan Komunikasi Terhadap Kinerja Karyawan Warung Mina Cabang Renon. E-Journal Manajemen Universitas Udayana, 6(6), 3398-3430.

https://media.neliti.com/media/publications/241770-pengaruh-gaya-

kepemimpinan-transformasio-ed7a $8 \mathrm{~b} 4 \mathrm{~d} . \mathrm{pdf} \% 0 \mathrm{~A}$

Robbins, Stephen P. (2009). Perilaku Organisasi, Buku 1. Jakarta: Penerbit Salemba Empat.

Robbins, Stephen P. dan Judge, Timothy A. (2015). Perilaku Organisasi Edisi 16. Jakarta Selatan. Salemba Empat.

Saqib Nawaz, M., Hassan, M., Hassan, S., Shaukat, S., \& Asadullah, M. A. (2014). Impact of Employee Training and Empowerment on Employee Creativity Through Employee Engagement: Empirical Evidence from the Manufacturing Sector of Pakistan. Middle-East Journal of Scientific Research, 19(4), 593-601. https://doi.org/10.5829/idosi.mejsr.2014.19.4.13618

Serim, H., Demirbağ, O., \& Yozgat, U. (2014). The Effects of Employees' Perceptions of Competency Models on Employability Outcomes and Organizational Citizenship Behavior and the Moderating Role of Social Exchange in this Effect. Procedia - Social and Behavioral Sciences, 150(1), 1101-1110. https://doi.org/10.1016/j.sbspro.2014.09.125

Sumarni, M. (2010). Pengaruh Organizational Commitment Dan Professional Commitment Terhadap Organization Citizenship Behavior. Jurnal Bisnis Dan Kewirausahaan, 4(2), 1-25. https://ekonomi.upy.ac.id/files/PENGARUH ORGANIZATIONAL 
COMMITMENT DAN PROFESSIONAL COMMITMENT TERHADAP ORGANIZATION CITIZENSHIP BEHAVIOR_MURTI SUMARMI_.pdf

Thao, L. T. T., \& Hwang, C. shu J. (2015). Factors Affercting Employee Performance - Evidence From Petrovietnam Engineering Consultancy J.S.C. Human Resource Management Journal, 43(1), 1-13. http://ir.meiho.edu.tw/bitstream/987654321/2774/2/FACTORS+AFFECTIN G+EMPLOYEE+PERFORMANCE.pdf

Wahyudi, I. W. (2013). Pengaruh Pelaksanaan Kepemimpinan, Komunikasi dan Lingkungan Kerja Fisik Terhadap Kepuasan Kerja Karyawan Pada PT. Karang Bali Asli Tur Denpasar. E-Jurnal Manajemen Unud, 2(10), 12291242. https://doi.org/10.1111/1467-9566.12522

Wanjiku, N. A., \& Lumwagi, N. (2014). Effect of Organisation Culture on Employee Performance in Non Govermental Organizations. International Journal of Scientific and Research Publications, 4(11), 1-12. www.ijsrp.org

Wiguna, I. D. G. E. C. (2015). Pengaruh Gaya Kepemimpinan, Komunikasi, Pendidikan dan Pelatihan Terhadap Kinerja Karyawan Pada PT. PLN (Persero) Distribusi Bali Area Bali Selatan. E-Jurnal Manajemen Unud, 4(9), 2527-2543. https://ojs.unud.ac.id/index.php/Manajemen/article/view/12900

Wirawan. (2009). Evaluasi Kinerja Sumber Daya Manusia: Teori, Aplikasi dan Penelitian. Jakarta: Penerbit Salemba Empat.

Zameer, H., Alireza, S., Nisar, W., \& Amir, M. (2014). The Impact of the Motivation on the Employee ${ }^{\mathrm{TM}_{\mathrm{S}}}$ Performance in Beverage Industry of Pakistan. International Journal of Academic Research in Accounting, Finance and Management Sciences, 4(1), 293-298. https://doi.org/10.6007/ijarafms/v4-i1/630 